\title{
Education and Training in Breast Cancer Surgery in Europe
}

\author{
Lynda Wyld $^{\mathrm{a}, \mathrm{b}}$ Isabel T. Rubio ${ }^{c, d}$ Tibor Kovacs $^{\mathrm{e}}$ \\ ${ }^{a}$ Department of Oncology and Metabolism, University of Sheffield Medical School, Sheffield, UK; ${ }^{b}$ Doncaster

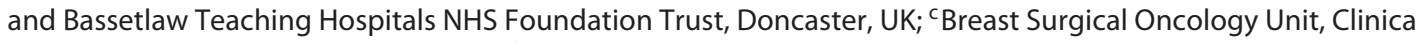 \\ Universidad de Navarra, Madrid, Spain; ${ }^{d}$ Universidad de Navarra, Pamplona, Spain; ${ }^{\mathrm{e} G u y ' s ~ H o s p i t a l ~ B r e a s t ~ U n i t, ~}$ \\ London, UK
}

\author{
Keywords \\ Breast cancer · Training · Education · Variation and \\ harmonization
}

\begin{abstract}
Background: The substantial increase in the complexity of breast cancer care in the last few decades has resulted in significant improvements in survival rates and also in the quality of life of breast cancer survivors. However, across Europe there are variations in outcomes and access to the latest techniques. Whilst much of this variance is due to differences in health economies between European member states, training variation may also play a part. Training in breast cancer surgery varies greatly across Europe, not only in its basal discipline (general surgery, gynaecology or plastic surgery) but also in the length of training and whether there is any requirement for specialist training. Several countries have been leading the way in training breast specialist surgeons (the USA, the UK, Australia and New Zealand) with dedicated 1- or 2-year fellowships either within or in addition to standard training. Access to such training is limited and consequently many women in Europe are still treated by generalists, potentially denying them access to the best care. This paper reviews the issues surrounding training provision in breast surgery and some of the challenges which need to be addressed to improve the current situation. Summary: Breast surgery training in Europe is of variable quality and duration, which may result in variations in the quality of care received by patients with breast cancer. Specialist training standards are urgently required which should be adopted by all European member states. Excellent models are available
\end{abstract}

in the USA, the UK and Australia and New Zealand on which to base this training. Key Messages: The quality of training in breast surgery needs to be upgraded and harmonised across Europe.

๑) 2019 S. Karger AG, Basel

\section{Introduction}

Breast cancer treatment has evolved substantially in the past 40 years resulting in an improvement in both survival rates and the quality of life of breast cancer survivors. Improvements have been across the spectrum of therapies, including diagnostics (both imaging and pathology), surgery, radiation oncology, medical oncology, genetics and psychological support. Perhaps more than with any other cancer, treatment is multimodal and cross disciplinary, requiring multidisciplinary expertise and interdisciplinary training [1].

Surgery in particular has seen a revolution in practice over the past 40 years. In the 1970s there was only one operation for breast cancer: mastectomy and full axillary node clearance. In present day practice, as a result of surgical de-escalation, there have been progressive increases in rates of breast conservation surgery [2] and sentinel node biopsy [3]. More complex axillary management algorithms in primary surgery and neoadjuvant settings (such as targeted axillary dissection [4]) have further added to the need for advanced level training. Similarly, the roll out of screening, necessitating a range of different guided breast conservative surgeries [5], such as radioactive seeds, intraoperative ultrasound and magnetic seeds,

\section{KARGER}

(c) 2019 S. Karger AG, Basel 


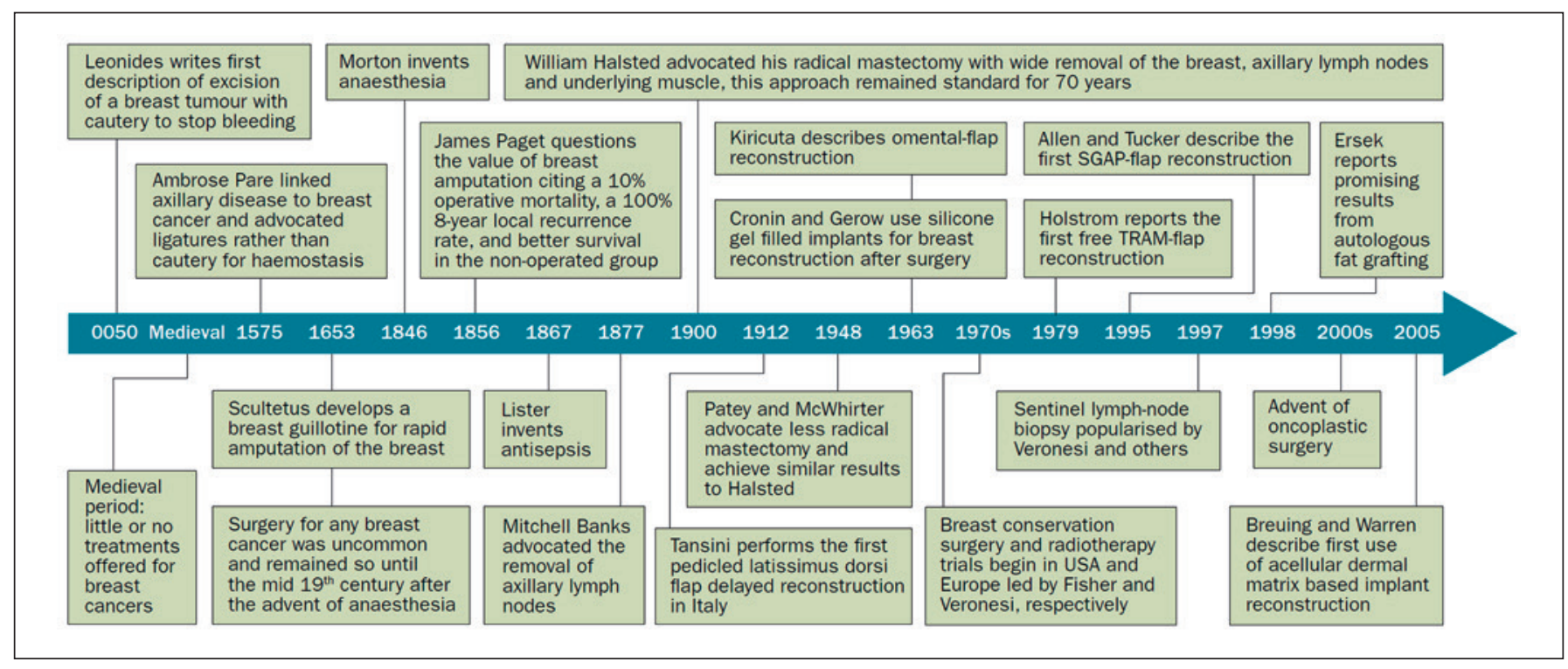

Fig. 1. Timeline for the evolution of breast cancer surgery. Reproduced with permission from Wyld et al. [8].

has all contributed to a substantial increase in the complexity of oncologic breast surgery. Running parallel to this has been a shift towards preservation of the aesthetics of the breast with the rise of post-mastectomy reconstruction and oncoplastic conservation techniques. As a result, there are whole atlases [6] and algorithms [7] for different oncoplastic conservation techniques to suit every breast size, shape and tumour location. In addition, the range of techniques for total breast reconstruction is expanding, ranging from an expanding armamentarium of free and pedicled tissue transfers to the use of implants and biological and synthetic meshes. The temporal progression of breast surgery is shown in Figure 1 [8].

The modern breast surgeon must therefore have a wide range of surgical techniques at their disposal. Add to this the requirement to integrate and coordinate an expanding range of increasingly sophisticated and effective adjuvant and neo-adjuvant therapy regimes and it is clear that breast surgery should no longer be provided by a generalist, but by a specialist surgeon [9]. There is evidence that surgeon specialization is associated with both enhanced survival outcomes (up to $8 \%$ improvement at 10 years) [10] and higher levels of patient satisfaction [11]. There is also evidence that case load correlates positively with outcomes, again supporting specialization at both surgeon [12] and hospital level [13]. Such skills require adequate training, certification and ongoing re-accreditation to ensure practitioners keep up to date with the rapid pace of change in this discipline. Whilst some countries have moved ahead in this regard, developing training programs, curricula and examinations, many countries have no specific breast surgery training. This means that many women still receive care from a non-specialist and may be denied the full range

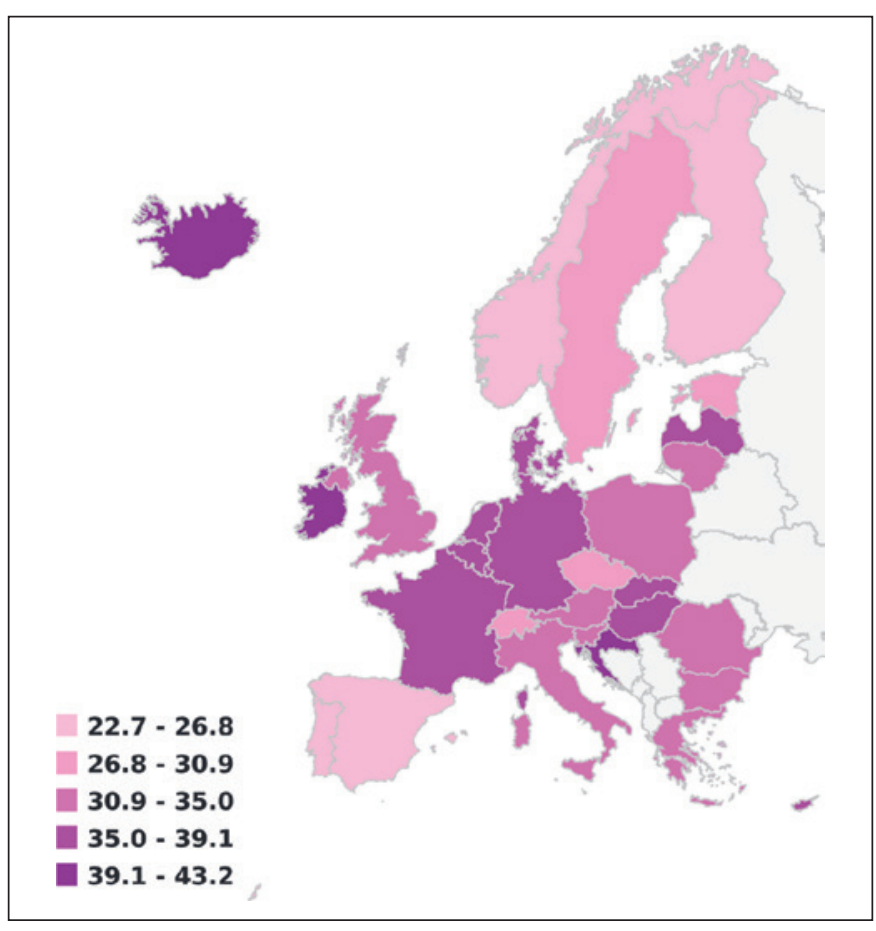

Fig. 2. Age-standardised mortality rates per 100,000 women in Europe. European Cancer Information System [14].

of modern treatment options and consequently suffer inferior outcomes. Breast cancer survival outcomes across the EU are highly variable, ranging from 74\% 5-year survival in Eastern Europe to 85\% in Northern Europe (Fig. 2) [14]. The causes of this variance are complex, reflecting differences in screening, breast awareness and health service funding variance and access to the latest therapies. However, training variation is probably also a factor. 


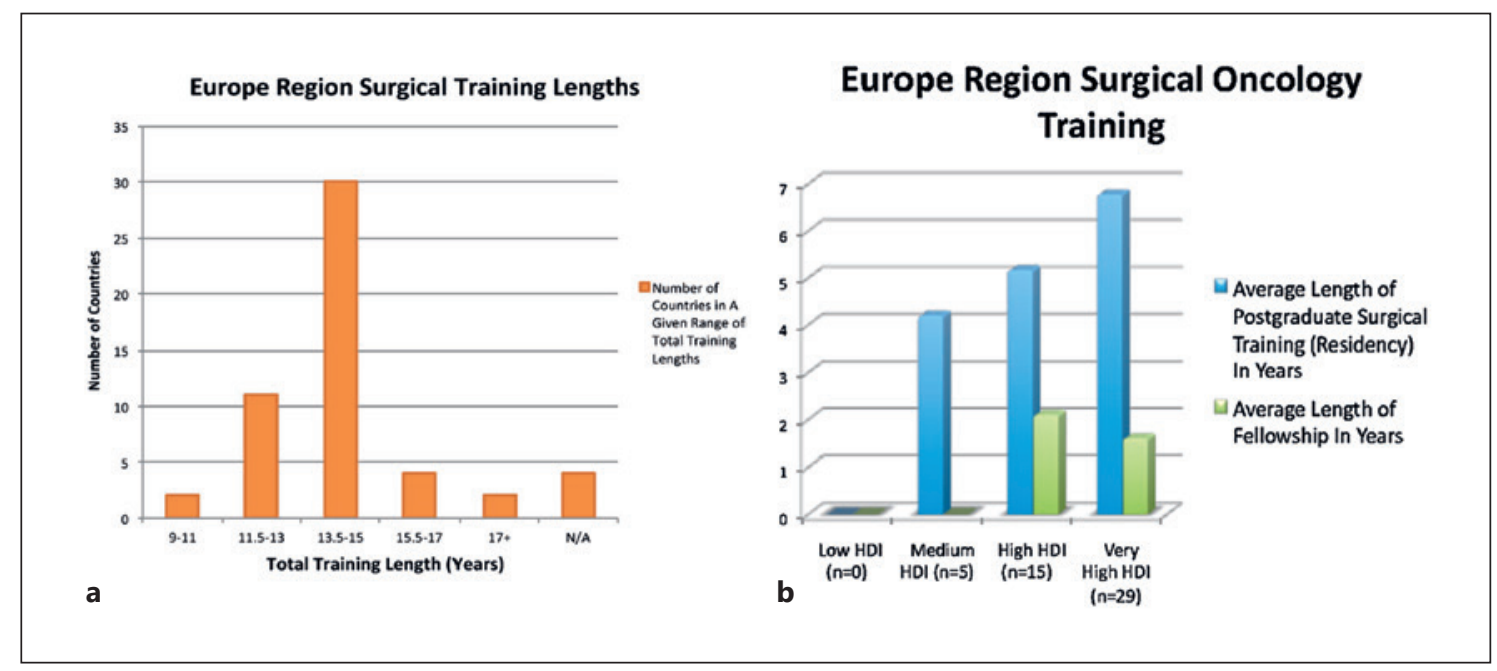

Fig. 3. Length of surgical training and cancer surgery residency (a) and duration of specialist fellowships in European countries (b). Reproduced from Are et al. [15].

Globally, training in surgery varies markedly in duration and the level of specialization (uptake of specialist fellowships for example). A recent global survey of cancer surgery training found wide variation between countries globally and within Europe. Training duration in Europe varied between 9 and 17 years, and the median duration of specialist fellowship training varied from 0 to 2 years (Fig. 3a, b [15]).

A recent survey of breast surgeons across Europe [16] revealed wide variation in training and specialization in breast surgery with $12 \%$ of surgeons treating fewer than 25 cases per year and only a third of surgeons self-identifying as breast specialists. Whilst $77 \%$ have had some focused oncoplastic training, $8 \%$ had none at all.

At present, breast surgery as a specialist discipline does not exist in any country, and practitioners are usually trained in general, gynaecological or plastic surgery. In most countries such generalist training will last between 4 and 6 years, resulting in certification in general, gynaecologic or plastic surgery. The breast component of this training will be variable and may be as little as a few months in a non-specialist breast unit. This certification gives the holder a license to treat breast cancer, and many women are treated by surgeons treating very small numbers of cases per year, sometimes outside of a formal multidisciplinary team [16].

\section{Breast Surgery as a Specialist Discipline}

In the UK, the General Medical Council (GMC) is currently reviewing the status of breast surgery and whether to recognise it as a specialist discipline in its own right or as a recognised sub-specialism of general surgery requiring a specific training pathway distinct from other areas of practice. At present, breast surgery is classed as a special interest within general surgery. The end of training examination (FRCS) permits a special interest to be designated and the exit exam tailored to this interest. Progress towards breast specialization in the UK has seen the majority of UK breast surgeons move away from provision of emergency surgery [17] and the establishment of a National Oncoplastic Training (TIG) fellowship scheme in 2002 which has trained 9 fellows per year via a centrally funded and appointed program [18]. The purpose of this was to pump prime the UK surgical workforce with skilled Oncoplastic trained surgeons who would themselves cascade their skills across all UK units as they themselves became trainers. This system however is too numerically small to include all UK trainees with a breast interest. This means than many surgeons complete their certified training without acquiring the necessary skills set and have to undertake post-certification fellowships which are unregulated. Much of the 6-year training time is spent acquiring the full range of general surgery skills which will not be necessary for breast practice and may be viewed as wasted training time, largely providing emergency service for the units they work in. As a result, the UK training authorities and the GMC are undertaking a review of breast surgery training with a view to creating either a hybrid model of training, giving more weight to specialised breast training and certification, or recognising breast surgery as a separate surgical discipline. The current system is recognised as flawed, and the majority of UK trainees with a designated breast interest feel that their breast surgery training is impeded by the necessity of general surgery training and would prefer a more specialised training pathway [19]. 


\section{Global Training Models}

Elsewhere in Europe in 2019, it is still the case that the majority of women are treated by a non-specialist trained general or gynaecological surgeon, sometimes with input from plastic surgery to provide reconstructive and oncoplastic input. Many women are therefore denied access to the latest advances in care, a fact which has drawn condemnation from patient advocacy groups. Until breast surgery is recognised as a specialist discipline, this is not likely to change because most sovereign member states of the EU regulate the training of surgeons within historically well-defined groups: general surgery and gynaecology. Accreditation is therefore as a general or gynaecological surgeon, and there is no requirement and often no mechanism for the attainment of these specialist skills. Within these disciplines, European law (European Specialist Medical Qualifications Order 1995 [20]) recognises and sets professional minimum standard of doctors across Europe, (which permits freedom of movement) but as breast surgery is not recognised as a discipline in its own right, there is no such requirement at the high level modern breast surgery requires. A directive from the EU, in support of some degree of specialization, would be helpful, and the European Commission has recently taken an interest in a range of issues relating to the quality and harmonization of breast care provision across Europe, of which training is hoped to be one element [21]. Recognition of breast surgery as a specialist discipline would be very helpful in moving this forwards.

Global models of breast surgery training are varied and address this issue with varying levels of success. Some of these models are reviewed below.

\section{The United States of America}

In the USA, breast surgery is part of general surgery but is recognised as a sub-specialism. Fellowships in breast surgery are available. These are not mandatory, and many women still undergo treatment for breast cancer with non-specialist surgeons. In the majority of cases, breast oncology surgery is performed by general surgeons and reconstructive surgery by plastic surgeons, usually working closely together. The American Society of Breast Surgeons, the American Society of Breast Diseases and Society of Surgical Oncology (SSO) have developed guidelines for breast fellowship training, and numerous fellowships are available to provide high level training for those wishing to do so [22]. The SSO developed its first breast fellowship program in 2004, and currently there are over 50 US centres offering over 60 breast fellowships. The scheme has a defined curriculum and sets out its training requirements in detail [23]. Candidates are nationally ranked and matched via a central process. The centres themselves have to be quality assessed and re-accredited every 5 years. The feedback from the fellows is excellent [24].

\section{United Kingdom}

In the UK in 2002 a new national training scheme commenced. Trainees with an interest in breast surgery with a background in general or plastic surgery were placed in centrally approved, high-quality training centres for 12 months to acquire high-level oncoplastic skills. The initiative was established by the Association of Breast Surgeons (ABS), The British Association of Plastic and Reconstructive Surgeons (BAPRAS) and UK training authorities which provided full funding for these posts. The intention was that these individuals would then pass on this skill set and upskill the entire breast surgery workforce over the subsequent decade. Nearly 200 fellows have now completed the scheme, and the majority of UK breast units now provide Oncoplastic services, so women may undergo both their oncology and reconstructive surgery in a seamless way. As a result, rates of immediate breast reconstruction have increased from 10 to $25 \%$ over the same time period [25], although rates are highly variable between UK regions [26]. Certification in breast surgery as a distinct entity is not yet a reality; however, the UK final training certification (certificate of completion of training in general surgery) requires passing the FRCS examination which allows the candidate to specify a breast special interest wherein the exam focuses on breast surgery to a higher level. There is the option to undertake an on-line UK master's degree in breast surgery, but the degree course is quite costly [27]. There is presently discussion with the medical regulator (the GMC) to allow breast surgery to be partially, or fully, separated from general surgery part way through training to allow all breast trainees, not just TIG fellows, to have more of their senior training focused on high level breast surgery skill acquisition. The preferred option for most UK breast surgical trainees is to work towards full separation in the future with breast recognised as a separate specialty [17].

\section{Australia and New Zealand}

In Australia and New Zealand, breast surgery is part of general surgery, but in 2010, in recognition of the increased complexity of breast surgery, a fellowship scheme was established to provide 1- or 2-year training posts on oncoplastic surgery [28]. This was led by "Breast Surgeons of Australia and New Zealand" (BreastSurgANZ). These posts are centrally advertised and appointed with up to 30 units offering training posts [29]. The first year of a 2-year program covers the intermediate level skills such as mastectomy and axillary clearance, and the second year covers higher-level oncoplastic and reconstructive surgery based around a standardised curriculum. Fellows have access to training days, covering elements of oncoplastic surgery, ultrasound and communication skills. At present, there is no exit examination. 
Table 1. Table reviewing the provision of breast surgery delivery, training and certification across Europe

\begin{tabular}{lllll}
\hline Country & $\begin{array}{l}\text { Specialties performing } \\
\text { breast surgery }\end{array}$ & $\begin{array}{l}\text { Undergraduate } \\
\text { breast training }\end{array}$ & Post-graduate breast training & $\begin{array}{l}\text { Mandatory examination to obtain } \\
\text { title of consultant breast surgeon }\end{array}$ \\
\hline Spain & GS, G & No & No & $\begin{array}{l}\text { No } \\
\text { UK }\end{array}$ \\
BS, GS, PS & No & Yes (OPS training desirable & $\begin{array}{l}\text { Yes (Royal College } \\
\text { of Surgeons exit exam) }\end{array}$ \\
Portugal & GS, G & No & No & No \\
Italy & GS, PS & No & No & No \\
Sweden & BS, GS, PS & No & Yes, UEMS exam & Yes \\
Netherlands & GS, PS & No & No & No \\
Poland & GS, SO, G, PS & No & No & No \\
Denmark & GS, PS & No & Yes, UEMS exam & No \\
Iceland & GS, PS & No & No & No \\
France & GS, G, PS & Yes & Yes & No \\
Hungary & GS, G, PS & No & No & No \\
Switzerland & GS, G, PS & No & Yes & In progress \\
Finland & GS, G, PS & Yes & Yes (not official) & No \\
Germany & G & Yes & Yes & No \\
Turkey & GS & Yes & Yes & No \\
\hline
\end{tabular}

BS, (oncoplastic) breast surgery; GS, general surgery; G, gynaecology; PS, plastic surgery (PS ${ }^{\text {a }}$ plastic surgery just for reconstructive elements); SO, surgical oncology.

In 2016, an optional online course, based on a standard curriculum, was launched to support these fellowship posts [30]. This was developed by the University of Sydney and may be taken to certificate or masters level, although it is quite costly, which is a deterrent to higher uptake rates amongst fellows. Feedback from trainees has been largely positive [30,31], although there are clearly some issues with variation between the different training posts [30].

\section{Portugal}

At present, breast fellowship training is limited in Portugal with few fellowships available at present (e.g., a 3- to 6-month breast fellowship is available at Champalimaud in Lisbon) but plans to develop a specific curriculum and examination are in development but, to date, specialist training is not mandatory [32].

\section{France}

Breast surgery is usually provided by gynaecologists. France has well-developed oncoplastic surgery training which usually follows completion of training in gynaecology. There is no formal examination.

\section{Canada}

Oncoplastic and specialist breast surgery training is not well developed in Canada with just a handful of fellowships in existence [33]; however, these are of high quality.

\section{Germany}

There are 2 levels of regulation. The first is that of the German Cancer Society, which mandates that all sur- geons who treat breast cancer in a certified centre (which covers about $90 \%$ of all cases of breast cancer) must treat at least 50 primary cases per year. In addition, the German Association of Reconstructive Surgery in Gynecology (AWO-Gyn) specifies that a certain number of cases need to be documented in a log book (including oncoplastic and reconstructive techniques), and there is also a practical examination.

As can be seen from the above, provision of high-quality training is possible but review of training across all European countries shows that the majority have no specific training system for breast surgery as shown in Table 1 (reproduced with permission from Rubio et al. [16]).

\section{Examination and Other Formal Qualifications in Breast Surgery}

The UEMS Examination

In 2010, a joint initiative by the Union of European Medical Specialists (the UEMS), the European Society of Breast Cancer Specialists (EUSOMA) and the European Society of Surgical Oncology (ESSO) led to the creation of a European Breast Exam. The exam is designed to test a candidate's expertise in breast cancer management at the level of completion of training. The exam has 3 parts:

- An initial eligibility assessment to ensure that the candidate has undergone at least 2 years of specialist training in a high-quality breast unit, has undertaken a specified number of index procedures and has published or presented a paper related to breast disease management. 
- A written examination in the format of a multiplechoice exam with 50 questions which may be taken at a range of locations online.

- An oral examination which tests higher-order skills in both the management of complex cases and also the interpretation of research data to ensure candidates are able to understand the latest developments in practice. The popularity of the exam has been increasing with up to 70 candidates per year sitting for the exam. The exam has a detailed syllabus [34] which is updated every 2 years and a textbook that mirrors the curriculum [35]. Examiners are drawn from senior members of the European Breast Fraternity. At present, the exam is not recognised for certification purposes in any European country, for the simple reason that breast surgery is not a recognised specialty at present, although it is accepted as evidence of expertise by some jurisdictions. The hope is that formal specialist recognition of the exam will eventually occur in some member states and in the interim, increasing numbers of breast surgeons will wish to sit the exam to increase their knowledge and testify to their expertise.

\section{University Qualifications}

There are several universities offering degree courses focused on breast surgery/breast cancer management. The 2 most widely established are those of the University of Ulm/European School of Oncology (ESO) Certificate of Competence in Breast Care and the University of East Anglia Master's degree course.

\section{Continuing Medical Education Certification}

The majority of European countries operate mandatory requirements for doctors to show evidence of continuing professional development, although only a minority mandate full re-accreditation. Because breast surgery is not yet a recognised discipline in surgery, there is no requirement for any specific educational content that relates to breast surgery. There are numerous good-quality courses available across Europe and globally.

Each year, there are many high-quality breast congresses which may focus on either show-casing the latest research, educational updates on best practice or a combination of the two. These are often focused on the oncological aspects of care or on oncoplastic and reconstructive elements and it is advised that both are necessary for best practice. Whilst many are lecture based, there are also many excellent hands on courses, some of which utilise cadavers to allow participants to try out the latest techniques.

\section{European Breast Surgery Initiative (BRESO)}

In recognition of the above difficulties, several European societies (ESSO, ESO, EUSOMA, EUROPA DONNA, EUBREAST, the UEMS and EICBC) have come to- gether to develop a standard pan-European curriculum for both knowledge and skill requirements for a fully trained breast surgeon. This initiative has been labelled the European Breast Surgery Initiative, BRESO. It is hoped that in the next few years this collaboration will result in widespread adoption of these standards and so improve the quality of care received by all European patients with breast cancer. The group will lobby for regulatory changes to improve the harmonization of training in breast surgery across Europe, increase the uptake of fellowships and specialist exams and try to develop a network of European training fellowships similar to those offered in the USA, UK and Australia and New Zealand. Clearly these are ambitious goals but, based on the success and impact of existing models, worthy of pursuing.

\section{Conclusion}

As can be seen from the above, training in breast surgery across Europe is highly variable and generally poorly regulated with a few notable exceptions (the UK, Germany, France).

This raises concern about the experience and expertise of surgeons delivering breast care and the impact this may have on patient experience and oncological outcomes. Regulation across Europe is challenging as the EU does not have a legislative role in controlling or harmonising training other than at the level of the undergraduate degree and at the level of completion of training in general surgery or gynaecology. At these 2 points, training should be equivalent, but the level of breast expertise expected within these much broader specialties is poor and inadequate for the demands of modern breast practice. However, because breast surgery is not recognised as a specialty in its own right, there is no mechanism for policing standards beyond this. Efforts to address this initially should focus on voluntary measures to enhance training, with high-quality fellowships, training courses, and examinations. Ultimately however, regulatory change will be required either by individual member states or via European directives, to recognise breast surgery as a specialist discipline within Europe to mandate improvements.

\section{Acknowledgement}

Thorsten Kuhn for advice about German Breast Surgery training.

\section{Disclosure Statement}

The authors have no conflicts of interest to declare. 


\section{Funding Sources}

None.

\section{References}

1 Benstead K, Turhal NS, O’Higgins N, Wyld L, Czarnecka-Operacz M, Gollnick $\mathrm{H}$, et al. Multidisciplinary training of cancer specialists in Europe. Eur J Cancer. 2017 Sep;83:1-8.

2 Garcia-Etienne CA, Tomatis M, Heil J, Friedrichs K, Kreienberg R, Denk A, et al.; eusomaDB Working Group. Mastectomy trends for early-stage breast cancer: a report from the EUSOMA multi-institutional European database. Eur J Cancer. 2012 Sep;48(13):1947-56.

3 Garcia-Etienne CA, Mansel RE, Tomatis M, Heil J, Biganzoli L, Ferrari A, et al.; EUSOMA Working Group. Trends in axillary lymph node dissection for early-stage breast cancer in Europe: impact of evidence on practice. Breast. 2019 Jun;45:89-96.

4 Caudle AS, Kuerer HM. Targeting and limiting surgery for patients with node-positive breast cancer. BMC Med. 2015 Jun;13(1):149.

5 Chan BK, Wiseberg-Firtell JA, Jois RH, Jensen K, Audisio RA. Localization techniques for guided surgical excision of non-palpable breast lesions. Cochrane Database Syst Rev. 2015 Dec;(12):CD009206.

6 Clough KB, Kaufman GJ, Nos C, Buccimazza I, Sarfati IM. Improving breast cancer surgery: a classification and quadrant per quadrant atlas for oncoplastic surgery. Ann Surg Oncol. 2010 May;17(5):1375-91.

7 Weber WP, Soysal SD, Fulco I, Barandun M, Babst D, Kalbermatten D, et al. Standardization of oncoplastic breast conserving surgery. Eur J Surg Oncol. 2017 Jul;43(7):1236-43.

8 Wyld L, Audisio RA, Poston GJ. The evolution of cancer surgery and future perspectives. Nat Rev Clin Oncol. 2015 Feb;12(2):115-24.

9 Rainsbury RM. Training and skills for breast surgeons in the new millennium. ANZ J Surg. 2003 Jul;73(7):511-6.

10 Gillis CR, Hole DJ. Survival outcome of care by specialist surgeons in breast cancer: a study of 3786 patients in the west of Scotland. BMJ. 1996 Jan;312(7024): 145-8.

11 Waljee JF, Hawley S, Alderman AK, Morrow M, Katz SJ. Patient satisfaction with treatment of breast cancer: does surgeon specialization matter? J Clin Oncol. 2007 Aug;25(24):36948.

12 Pass HA, Klimberg SV, Copeland EM 3rd. Are "breast-focused" surgeons more competent? Ann Surg Oncol. 2008 Apr;15(4): 953-5.

\section{Author Contributions}

L.W., I.T.R., and T.K. all contributed to the drafting and editing of the document.
13 Peltoniemi P, Peltola M, Hakulinen T, Häkkinen U, Pylkkänen L, Holli K. The effect of hospital volume on the outcome of breast cancer surgery. Ann Surg Oncol. 2011 Jun; 18(6):1684-90.

14 European Cancer Information System. Incidence and mortality 2018. https://ecis.jrc.ec. europa.eu/. Accessed July 2019.

15 Are C, Caniglia A, Malik M, Cummings C, Lecoq C, Berman R, et al. Variations in training of surgical oncologists: proposal for a global curriculum. Eur J Surg Oncol. 2016 Jun;42(6):767-78

16 Rubio IT, Wyld L, Esgueva A, Kovacs T, Cardoso MJ, Leidenius M, et al. Variability in breast cancer surgery training across Europe: an ESSO-EUSOMA international survey. Eur J Surg Oncol. 2019 Apr;45(4):567-72.

17 Kim BD, Potter A, Langlands S, Weston-Petrides F, Ashken G, Benson L, et al. Is the current training pathway for oncoplastic breast surgeons fit for purpose? Bull R Coll Surg. 2019 Feb;101(2):69-75.

18 Joint Committee on Surgical Training. Oncoplastic Breast Surgery, training Interface group (TIG) Fellowships. https://www.jcst. org/training-interface-groups/oncoplasticbreast-surgery/, 2019.

19 Back DB, Kwon KJ, Choi DH, Shin CY, Lee J, $\mathrm{Han} \mathrm{SH}$, et al. Chronic cerebral hypoperfusion induces post-stroke dementia following acute ischemic stroke in rats. J Neuroinflammation. 2017 Nov 9;14(1):216.

20 European Commission. Free movement of professional qualifications in practice. https:// ec.europa.eu/growth/single-market/services/ free-movement-professionals/qualificationsrecognition/automatic_en, 1995.

21 Mansel R. European Initiative on Breast Cancer. https://ecibc.jrc.ec.europa.eu/, 2019.

22 Teshome M, Kuerer HM. Training of breast surgical oncologists. Linchuang Zhongliuxue Zazhi. 2016 Jun;5(3):43

23 Society of Surgical Oncology. Breast Surgical Oncology Fellowship Curriculum and Minimum Training Requirements. https://www. surgonc.org/wp-content/uploads/2019/06/ 2019-Breast-Curriculum-and-TrainingRequirements-Final.pdf, 2019.

24 Sclafani LM, Bleznak A, Kelly T, El-Tamer MB. Training a new generation of breast surgeons: are we succeeding? Ann Surg Oncol. 2012 Jun;19(6):1856-61.
25 Jeevan R, Mennie JC, Mohanna PN, O’Donoghue JM, Rainsbury RM, Cromwell DA. National trends and regional variation in immediate breast reconstruction rates. Br J Surg. 2016 Aug;103(9):1147-56.

26 Jeevan R, Cromwell DA, Browne JP, Caddy CM, Pereira J, Sheppard C, et al. Findings of a national comparative audit of mastectomy and breast reconstruction surgery in England. J Plast Reconstr Aesthet Surg. 2014 Oct; 67(10):1333-44.

27 Down SK, Pereira JH, Leinster S, Simpson A. Training the oncoplastic breast surgeon-current and future perspectives. Gland Surg. 2013 Aug;2(3):126-7.

28 Yunaev M, Hingston G. Oncoplastic breast surgery in Australia and New Zealand-2014 and beyond. Gland Surg. 2014 Feb;3(1):7780.

29 Breast Surgeons of Australia and New Zealand. Post Fellowship Training in Breast Surgery. https://www.breastsurganz.org/education/pft-program-in-breast-surgery/, 2019.

30 Spillane AJ, Flitcroft KL, Warrier S, Katelaris AG. Evaluation of a structured clinical program and formal coursework in breast surgeon training in Australia and New Zealand. Eur J Surg Oncol. 2019 May;pii:S07487983(19)30452-4.

31 Sood S. Perceptions of increasing the complexity and commitment required for training breast surgeons: perspective of a post-fellowship trainee. ANZ J Surg. 2016 Sep;86(9):6389

32 Cardoso MJ, Macmillan RD, Merck B, Munhoz AM, Rainsbury R. Training in oncoplastic surgery: an international consensus. The 7th Portuguese Senology Congress, Vilamoura, 2009. Breast. 2010 Dec;19(6):538-40.

33 Maxwell J, Arnaout A, Hanrahan R, Brackstone M. Training oncoplastic breast surgeons: the Canadian fellowship experience. Curr Oncol. 2017 Oct;24(5):e394-402.

34 European Union of Medical Specialists. UEMS Breast Surgery Examination Syllabus. https://www.uemssurg.org/__data/assets/ pdf_file/0003/57918/Breast-Surgery-syllabus-2018-final.pdf, 2018.

35 Wyld LM, Leidenius C, Senkus-Konefkas ME editors. Breast Cancer Management for Surgeons. A European Multidisciplinary Textbook. Berlin: Springer; 2017. 